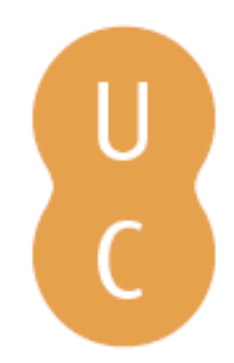

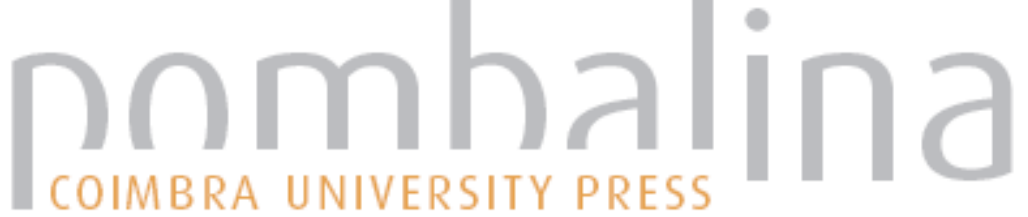

\section{Contribuição do sistema de informação geográfica e técnicas geoespaciais aplicadas ao estudo geotectônico: sismicidade em Goiás}

\author{
Autor(es): $\quad$ Silva, Alexandre Henrique Cardoso do Vale e; Nunes, Fabrizia Gioppo \\ Publicado por: Imprensa da Universidade de Coimbra \\ URL \\ persistente: URI:http://hdl.handle.net/10316.2/37059 \\ DOI: $\quad$ DOI:http://dx.doi.org/10.14195/978-989-26-0983-6_6 \\ Accessed : $\quad$ 26-Apr-2023 13:54:38
}

A navegação consulta e descarregamento dos títulos inseridos nas Bibliotecas Digitais UC Digitalis, UC Pombalina e UC Impactum, pressupõem a aceitação plena e sem reservas dos Termos e Condições de Uso destas Bibliotecas Digitais, disponíveis em https://digitalis.uc.pt/pt-pt/termos.

Conforme exposto nos referidos Termos e Condições de Uso, o descarregamento de títulos de acesso restrito requer uma licença válida de autorização devendo o utilizador aceder ao(s) documento(s) a partir de um endereço de IP da instituição detentora da supramencionada licença.

Ao utilizador é apenas permitido o descarregamento para uso pessoal, pelo que o emprego do(s) título(s) descarregado(s) para outro fim, designadamente comercial, carece de autorização do respetivo autor ou editor da obra.

Na medida em que todas as obras da UC Digitalis se encontram protegidas pelo Código do Direito de Autor e Direitos Conexos e demais legislação aplicável, toda a cópia, parcial ou total, deste documento, nos casos em que é legalmente admitida, deverá conter ou fazer-se acompanhar por este aviso.

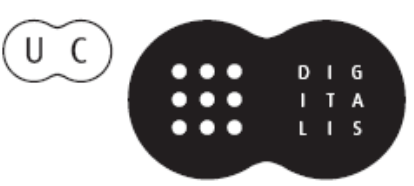




\section{$\forall$ \\ TAS DAS I JORNADAS LUSÓFONAS DE CIÊNCIAS E TECNOLOGIAS DE INFORMAÇÃO GEOGRÁFICA}

Editores

José Gomes dos Santos

Cidália Fonte

Rui Ferreira de Figueiredo

Alberto Cardoso

Gil Gonçalves

José Paulo Almeida

Sara Baptista 


\begin{abstract}
A RTI G O 6
CONTRIBUIÇÃO DO SISTEMA DE INFORMAÇÃO GEOGRÁfiCA E TÉCNICAS GEOESPACIAIS APLICADAS AO ESTUdO GEOTECTÔNICO - SISMICIDAdE EM GOIÁs
\end{abstract}

do VALE e SILVA, Alexandre Henrique Cardoso ${ }^{1}$ E NUNES, Fabrizia Gioppo ${ }^{2}$

\footnotetext{
${ }^{1}$ Instituto Militar de Engenharia; Subdivisão de Cursos de Pós-Graduação (SD/1); Seção de Engenharia Cartográfica - SE/6; Praça General Tibúrcio, 80 - Praia Vermelha; 22290-270 - Rio de Janeiro - RJ - Brasil Tel: 55 (62)8249-2072; e-mail: alexandre.vale@ime.eb.br

${ }^{2}$ Universidade Federal de Goiás; IESA - Instituto de Estudos Sócio-Ambientais ; Laboratório de Processamento de Imagem e Geoprocessamento - Lapig; Campus Samambaia CEP: 74.001-970 Caixa Postal 131, Goiânia - Brasil; Tel: 55 (62) 3521 - 1360; e-mail: fabrizia.iesa.ufg@gmail.com
}

\title{
RESUMO
}

Fenômenos sismológicos são inerentes à dinâmica da Terra, logo, ao observar as ocorrências de eventos sísmicos no estado de Goiás percebe-se uma disposição maior de registros em determinadas regiões. A complexidade do estudo sismológico se torna maior quando referente à tectônica intraplacas. No entanto, mediante ao uso de técnicas de geoprocessamento, bem como, da aplicação metodológica de análise geoespacial, para o tratamento de registros sísmicos, pode-se entender os padrões pontuais na identificação de áreas de clusters, representados em produtos cartográficos. Sabe-se que terremotos até o momento não são previstos e nem serão evitados, porém, a organização das informações de ocorrências sísmicas em ambientes de Sistema de Informação Geográfica, contribui na análise dos fatos relacionados aos abalos tectônicos, promovendo um diagnóstico para o zoneamento do potencial sismológico da região de estudo. Após análise dos mapas gerados em associação a geologia estrutural e a geofísica, pode-se observar um aglomerado pertinente 
à porção setentrional do estado. Isso indica que a densidade de tremores intraplacas, na região norte próximo ao lineamento transbrasiliano, está relacionada à localização da litosfera onde a crosta é mais fina.

\title{
PALAVRAS-CHAVE
}

Sistema de Informação Geográfica, Geotectônica, Sismicidade intraplaca, Análise espacial.

CONTRIBUTION OF GEOGRAPHIC INFORMATION SYSTEM AND GEOSPATIAL TECHNIQUES APPLIED TO STUDY THE GEOTECTONIC - SEISMICITY IN GOIÁS

\begin{abstract}
Seismological phenomena are inherent to the dynamics of the Earth, immediately, observing occurrences of seismic events in the state of Goiás, perceives a greater disposition of records in certain regions. The complexity of seismological study becomes greater when referring to intraplate tectonics. However by using GIS techniques, methodological application of spatial analysis for the treatment of seismic records, can understand the specific patterns to identify areas of clusters represented in cartographic products. It is known that earthquakes so far are not provided and will not be avoided but, the organization of information in environments of seismic occurrences of Geographic Information System, contributes to the analysis of the facts related to tectonic quakes and so, promote a diagnosis for zoning the seismological potential of the study area. After analyzing the maps generated in association with structural geology and geophysics, one can observe cluster the northern portion of the state. This indicates that where the density of tremors intraplate in the northern region near the lineament Transbrasiliano, is related to the location of the lithosphere where the crust is thinner.
\end{abstract}

\section{KEYWORDS}

GIS, Geotectonics, Intraplate seismicity, Spatial analysis

\section{INTRODUÇÃO}

No enquadramento da fenomenologia geoestutural brasileira, a maioria dos abalos sísmicos são eventos raros de serem sentidos pela população. Porém casos de magnitude $>6,0$ na escala Richter já ocorreram no país. O estudo sismológico se faz necessário para o entendimento maior das camadas do interior da Terra, compreendendo os impactos que as ondas 
de choque provocam na superfície.

Ao observamos a dinâmica sísmica do estado de Goiás, estimula-se uma reflexão a respeito das condições geofísicas locais, para a seguridade do potencial de uso antrópico. Os registros sismos coletados no Observatório Sismológico da Universidade de Brasília (UnB), no período de 1973 a 2013, tem demostrado um número considerável de abalos nas mesorregiões do norte e noroeste goiano, em relação às outras mesorregiões do estado, porém de magnitude moderada, < 5,2 na escala Richter. É relevante analisarmos as regiões em destaque, interpretando os dados geotectônicos, na visão da distribuição de padrões espaciais, dos pontos de ocorrência deste fenômeno, como uma corroboração ao desenvolvimento de modelos que buscam explicações para os eventos de terremotos no Brasil.

O geoprocessamento e suas ferramentas computacionais consistem em um exemplo de técnicas, que tem apresentado um amplo auxílio para o tratamento de informações espaciais, fazendo parte do universo geotecnológico, que caracteriza a organização das informações geográficas.

Segundo Câmara et al. (2001) são considerados três tipos de dados relacionados a problemas de analise espacial: (a) Áreas com Contagens e Taxas Agregadas, (b) Superfícies Contínuas e, (c) Eventos ou Padrões Pontuais, sendo este último à localização espacial do fenômeno, como o fator principal de análise associados a padrões aleatórios ou aglomerados das disposições pontuais.

A análise desenvolvida em plataformas SIG, permite a interpretação mais coerente do fenômeno estudado, comportando um nível de precisão onde às variáveis presentes são organizadas de acordo com a proposta do projeto, que propende à compreensão das aglomerações das ocorrências sísmicas no estado de Goiás. No intuito de atender esta proposta, o presente trabalho objetiva-se a análise da distribuição de arranjos espaciais da ocorrência de eventos sísmicos em Goiás, reconhecendo áreas de cluster, a partir do emprego da técnica de Kernel na identificação de padrões pontuais, bem como a correlação destes resultados com informações geológicas e geofísicas existentes. 


\section{APRESENTAÇÃo DO TEMA}

\subsection{Contexto geoestrutural}

Para entender a sismicidade brasileira, é importante compreender o contexto estrutural geológico do país. O Brasil está inteiramente localizado na plataforma Sul-Americana de idade pré-cambriana. Uma porção relativamente estável dividida em escudos pré-cambrianos e coberturas fanerozóicas, localizada a leste da Cadeia Andina, onde esta corresponde à área instável do continente.

Os embasamentos pré-cambrianos são escudos cristalinos caracterizados por rochas ígneas e metamórficas e são relativamente estáveis se tratando da tectônica. Esses embasamentos são atribuídos no conceito geológico, como porções da litosfera constituídas por substratos de origem arqueano e proterozóico. Já as coberturas fanerozóicas são estruturas sedimentares intracratônicas, herdadas do ciclo Brasiliano-Pan-Africano (MILANI \& THOMAZ FILHO, 2000).

A dinâmica geológica estrutural do Brasil faz com que a atividade sísmica presente no país, seja muito inferior aos abalos ocorridos nas bordas das placas, por exemplo, no contato entre as placas de Nazca e a placa Sul-Americana, porém, isso não quer dizer que a região seja assísmica. Devido a sua localização na porção central da placa da América do Sul, a sismicidade presente no território brasileiro é de origem intraplacas.

Explicar as origens de sismos intraplacas não é uma tarefa fácil. Zonas de fraqueza e concentração de tensões são alguns modelos propostos na tentativa de uma compreensão dessa atividade. É sabido que os abalos ocorridos nesses locais, em sua maioria, têm baixa e moderada intensidade, são decorrentes das tensões geradas por parte dos sismos tectônicos, originados entre as fronteiras das referidas placas (JOHNSTON \& KANTER, 1989). Todavia, alguns sismos podem ter grande magnitude como no caso de Porto dos Gaúchos no Mato Grosso com magnitude de 6,2 e em Vitória no Espírito Santo com magnitude de 6,1 ambos no ano de 1955 registrados por pesquisadores do exterior, pois, naquela situação praticamente não existiam registros sismológicos no país. 
Assumpção e Sacek (2013) pesquisando as anomalias gravimétricas no Brasil Central constatam que, onde a crosta terrestre é mais fina os abalos sísmicos se concentram. No mesmo artigo, os pesquisadores ressaltam que:

Modelaram as anomalias da gravidade no Brasil Central, supondo que o excesso de massa, causandor das anomalias isostáticas é devido a variações da espessura crustal. [...] a crosta estreita ocorre ao longo da zona do arco magmático e do Maciço de Goiás, fazendo um paralelo a região de alta gravidade. 'Soares et al. (2006) já haviam sugerido uma correlação das zonas citadas com uma crosta fina. Interpretando as anomalias Bouguer, de acordo com a teoria da Topografia de Moho'. Verificaram que no meio aquoso, que se refere à porção do manto, há uma área de baixa altitude e alta gravidade, coincidente com a zona sísmica, citada (tradução livre dos autores).

Para melhor entender a situação da espessura da crosta terrestre a Figura 1, ilustra a relação do manto no Brasil e nos Andes, mostrando que a profundidade é maior na parte oeste do continente Sul-Americano.

A compreensão dos esforços crustais é de fundamental importância para o estudo da sismicidade intraplaca e para o entendimento, dos processos dinâmicos das atividades, responsáveis pela movimentação e pela formação das placas litosféricas (ZOBACK, 1992 apud LOPES, 2008).

Da energia liberada pelos sismos, no planeta, 10\% estão relacionados à sismicidade intraplaca (JOHNSTON, 1989 apud LOPES 2008). O estudo desses esforços reconhece os mecanismos tectônicos que deformam as placas litosféricas, possibilitando, a determinação mais concisa do risco sísmico associados a grandes obras de engenharia, e a identificação de regiões onde poderão ocorrer futuros abalos intraplaca. (LOPES, 2008).

\subsection{Estimador de Kernel}

Para a análise espacial de dados geográficos, é necessário um fenômeno, onde este tenha uma localização no espaço. Na simbologia cartográfica, tal fenômeno pode ser representado por pontos e analisados de acordo com métodos de análises espaciais. 


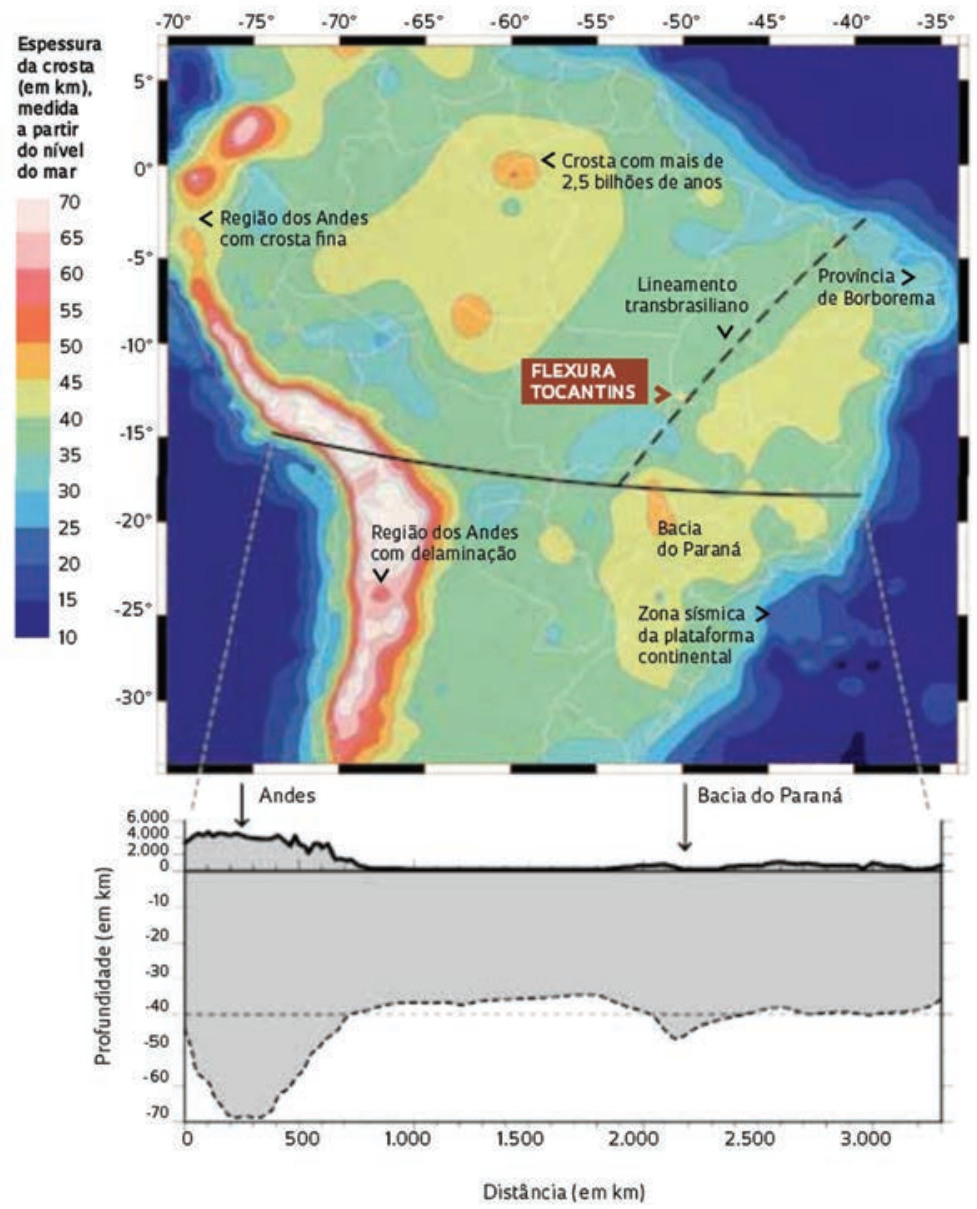

Figura 1 - Espessura da crosta terrestre no Brasil e nos Andes Fonte: Assumpção (IAG/USP, 2013)

Um dos métodos de análise do comportamento da distribuição pontual é o estimador de Kernel, que possibilita a estimação da densidade do evento em toda a área de interesse, mesmo em regiões onde o processo não tenha gerado nenhuma ocorrência real. Segundo Botev et al. (2010) o estimador de densidade de Kernel é uma técnica importante, para a análise estatística de dados. É considerado, como um estimador probabilístico e não paramétrico, ou seja, consiste em estimar o número esperado de eventos por unidade de área. Para os autores (op. cit.) a vantagem da abordagem não paramétrica é que esta oferece uma maior flexibilidade, 
na modelagem de um determinado conjunto de dados pontuais, ao contrário dos clássicos estimadores paramétricos.

De acordo com Matsumoto e Flores $(2012,96)$ o estimador de Kernel é uma técnica de estatística espacial que demonstra onde estão alocadas as concentrações de eventos pontuais em um plano. Quando este estimador é utilizado em um SIG, gera uma interpolação que se insere sobre as bases cartográficas, identificando o fenômeno georreferenciado no espaço geográfico e, destacando, a localização em que ocorre a maior ou menor frequência das concentrações do fenômeno analisado.

Em suma, pode-se avaliar que o estimador de Kernel é uma técnica que detecta a ocorrência de distribuições de eventos em padrões de aglomerados, ou a ocorrência destes, de forma aleatória. Este estimador consiste em uma função bidimensional, a qual se define uma largura de banda, fazendo-se a contagem de pontos dentro da região de influência, ponderados pela distância de cada um à localização de interesse. Como produto final, os resultados estarão arranjados em um plano cujo valor será proporcional à frequência de amostras por unidade de área, obtêm-se os cálculos quanto ao seu valor de densidade (BAILEY \& GATRELL, 1995).

Segundo Câmara e Carvalho $(2002,5)$ para efeito de cálculo são considerados como parâmetros básicos: (a) um raio de influência $(\tau \geq 0)$ que define a vizinhança do ponto a ser interpolado, controlando o "alisamento" da superfície gerada e; (b) uma função de estimação com propriedades de suavização do fenômeno. O raio de influência define a área centrada no ponto de estimação central "S" que indica quantos eventos "Si" contribuem para a estimativa da função de densidade " $\lambda$ ". O princípio esquemático do estimador de densidade de Kernel pode ser observado na Figura 2. 


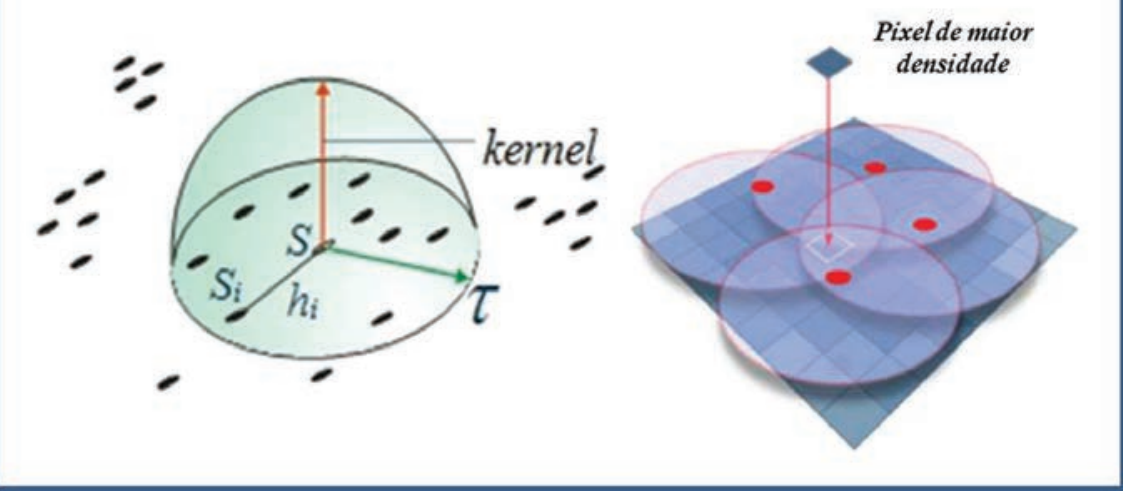

Figura 2 - Representação da ação do estimador de densidade de Kernel, sobre uma distribuição de pontos no espaço

Para a verificação dos eventos sismológicos, foram utilizados os dados cedidos pelo Observatório Sismológico da UnB. Os dados do observatório sismológico descrevem as informações dos abalos sísmicos no estado de Goiás, entre o período de 1973 até 2008. Foi utilizada também a compilação de ocorrências sísmicas do Websisbra, um Sistema de Informação Geográfica Web para a Análise de Fenômenos Sismológicos, objetivando completar os registros até o ano 2013. Todos os dados utilizados no presente artigo foram trabalhados no datum SIRGAS 2000 que obrigatoriamente é o modelo matemático da representação da superfície terrestre oficial do Brasil, não tendo problemas de compatibilidade. O levantamento foi contemplado por dados disponíveis em literaturas sobre o estudo de métodos tomográficos (IAG/USP) para obter informações das propriedades físicas da região do Brasil Central.

No decorrer das análises, para aplicação mais detalhada do estimador de Kernel, foi utilizada a ferramenta de análise espaciais, Mapa de Kernel, do aplicativo TerraView. O TerraView é um software de Sistema de Informação Geográfica, de domínio público, desenvolvido pelo Instituto Nacional de Pesquisa Espacial brasileiro (INPE), com ferramentas de análises espaciais, de fácil manuseio.

São vários os tipos de estimadores de Kernel: nornal, quártico, triangular, exponencial negativo e uniforme. No caso deste trabalho, foi utilizado um 
Kernel Quártico, que é o modelo adotado pelo aplicativo TerraView, para obter a estimativa da densidade de padrão de pontos. A função Quártica dá mais peso aos pontos próximos do que aos distantes, sendo o decréscimo gradual. Para Santos et al. (2012) o Kernel, como uma função de suavização, deve ser simétrica à origem. Assim, segundo os autores (op. cit.), uma das melhores soluções é aplicar um Kernel Quártico.

O aplicativo TerraView, possibilita a opção de adaptar o raio do círculo de vizinhança, ou seja, durante o processamento foi utilizada a opção Kernel Adaptativo. Essa alternativa calcula automaticamente o raio, considerando o número de eventos e a dimensão da unidade de área avaliada.

A ferramenta Mapa de Kernel permitiu o cálculo da função Quártica para a análise espacial da: (a) densidade, (b) média de movimento espacial e, (c) probabilidade dos eventos pontuais, com o atributo magnitude ativo. Por tanto, não considerou apenas a estimativa da frequência de pontos por unidade de área, mais também, o grau da magnitude dos sismos na escala Richter, ou seja, o cálculo do peso da desigualdade de importância dos eventos registrados e armazenados na tabela de atributo do banco de dados operacional.

Se tratando sobre o raio, que é um parâmetro importante para a representação cartográfica, no sentido do estimador de Kernel, para as ocorrências sísmicas, foi utilizado também o Kernel adaptativo. Onde é feito um cálculo para o raio automático que considera o número de eventos e a área.

Para efeito de zoneamento de risco foi calculada a densidade do evento por unidade de área, sendo as delimitações municipais, a unidade de área territorial, selecionada no estudo para a captura e representação dos dados quantitativos apresentados. A Figura 3 ilustra o esquema de aplicação da ferramenta Mapa de Kernel, do software TerraView, utilizada na elaboração dos mapas de riscos de sismo por municípios. 


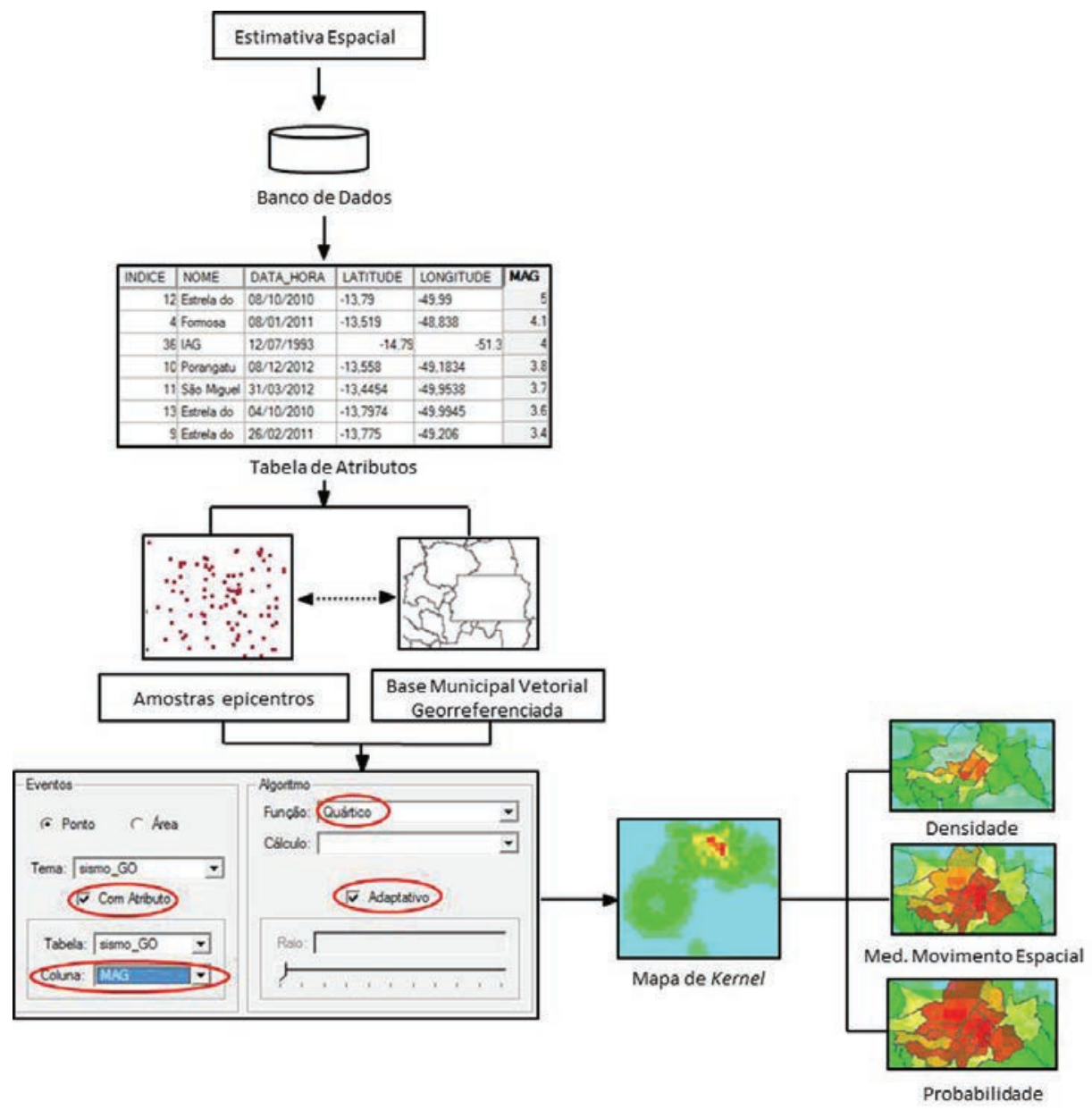

Figura 3 - Esquema utilizado pelo estimador de Kernel, no processamento de análise espacial dos pontos de epicentros registrados na Estação Sismológica da UnB, entre o período de 1973 a 2013

\section{DISCUSSÃO DOS RESULTADOS}

O tratamento das informações sismológicas do estado de Goiás foi realizado visando à caracterização espaço-temporal da sismicidade e sua correlação com as estruturas geológicas e geofísicas locais, de forma a obter a configuração do potencial sísmico da região. Ao compilar os dados do observatório sismológico, foi gerado um produto cartográfico que posiciona a distribuição e magnitude das ocorrências do evento nas mesorregiões do estado (Figura 4). 


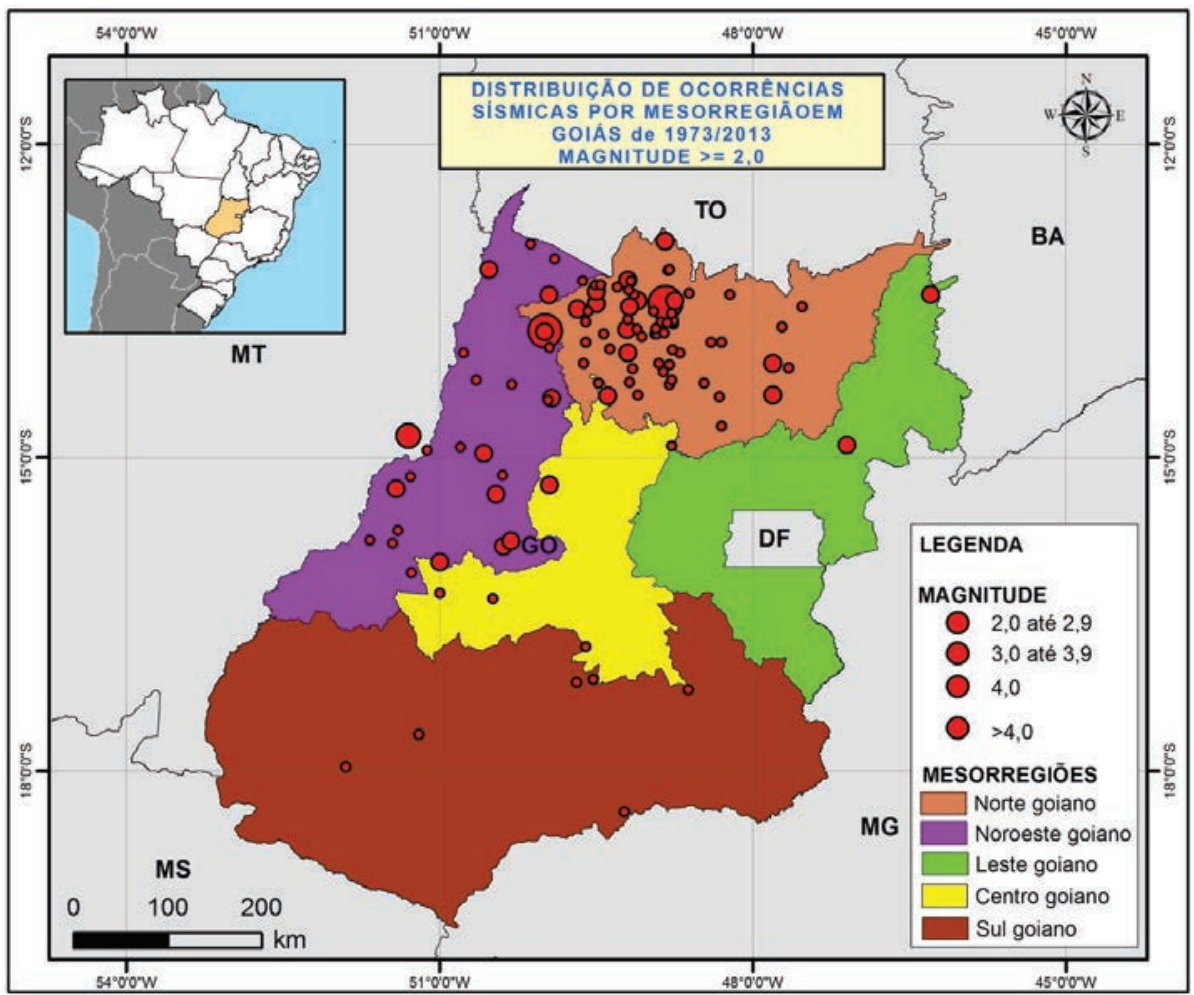

Figura 4 - Mapa da magnitude de ocorrências sísmicas nas mesorregiões do estado de Goiás

Da derivação das informações contidas na Figura 4, interpreta-se que as regiões leste, central e sul do estado de Goiás não concentram muitos registros de abalos geotectônicos intraplacas, concentrando a densidade de registros e os maiores pesos da magnitude sísmica, para as mesorregiões noroeste e norte, em especial, a essa última.

Ao processar os dados em ambiente SIG utilizando técnicas de geoprocessamento para a análise espacial de Kernel, foi gerado um produto cartográfico, enfocando, as principais regiões da densidade sísmica de Goiás, no que se refere às estruturas geológicas da região (Figura 5). Da organização destes dados e elaboração do produto cartográfico, observa-se que a disposição das ocorrências sísmicas em Goiás, apresenta-se com maior grau de frequência na porção norte do estado, sobre a estrutura geológica da Província Tocantins. 


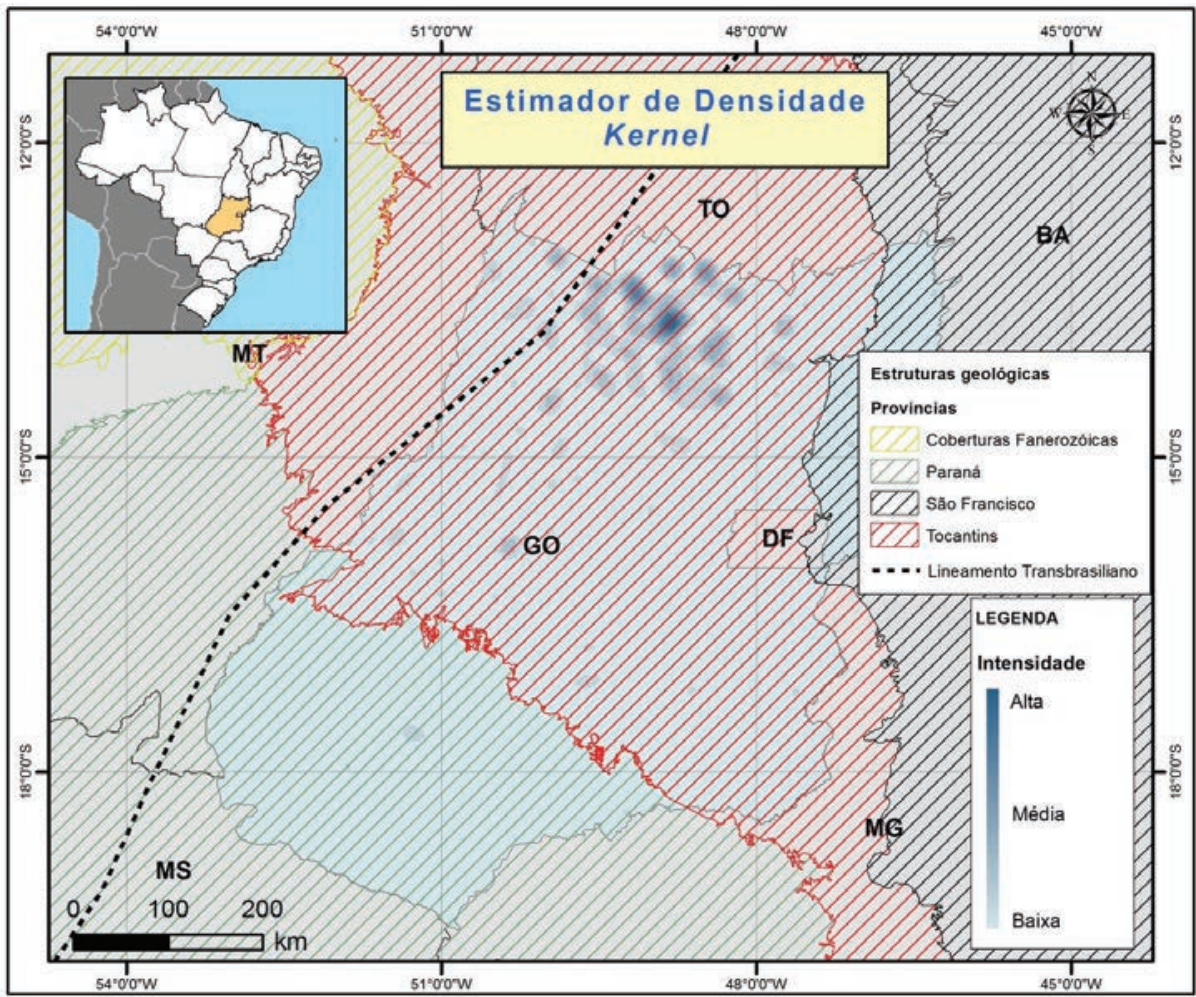

Figura 5 - Mapa de densidade sísmica do estado de Goiás

Dentro da caracterização do contexto geológico presente, as ocorrências destes sismos estão representadas em toda a província Tocantins (Figura 5), mais precisamente a leste do lineamento transbrasiliano, que corresponde a uma zona de fraqueza litosférica, com cerca de $2.700 \mathrm{~km}$ de extensão no território brasileiro. Nesta zona de fraqueza, concentram-se os esforços gerados nos limites das grandes placas tectônicas, onde em tempo futuro são liberadas as tensões, assim, sendo um potencial para sismicidade intraplacas.

Nota-se também a proximidade da zona sísmica Goiás-Tocantins com a densidade das ocorrências na região. Um paralelismo do lineamento transbrasiliano com a zona citada. A localização da mesma pode ser observada na Figura 5.

A Figura 6 apresenta os resultados da aplicação do processo estocás- 
tico de interpolação dos pontos de epicentros, pelo estimador de Kernel, utilizando as ferramentas computacionais do TerraView. No caso referente à concentração de registros dos eventos sísmicos, nos municípios goianos verifica-se que tanto para os cálculos de densidade, média de movimento espacial e de probabilidade, há a formação de um cluster de forte densidade sobre os municípios pertencentes à porção norte do estado.

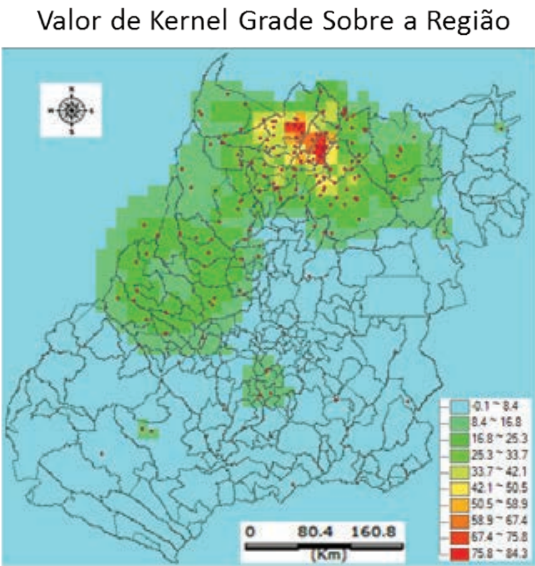

Cálculo da Média de Movimento Espacial

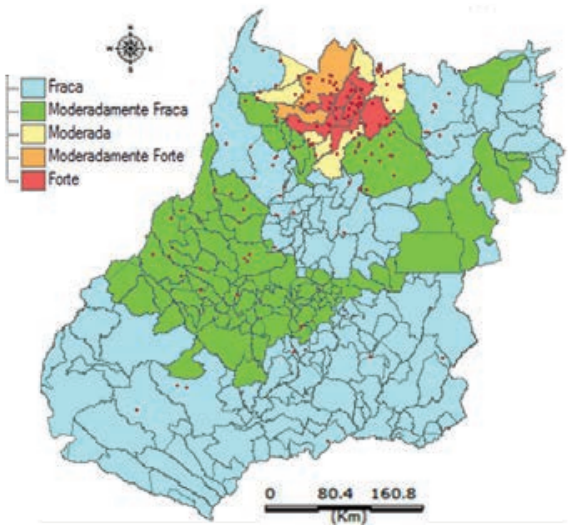

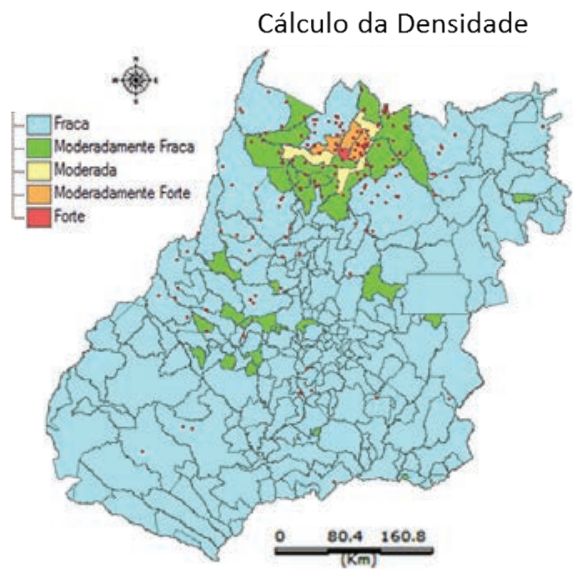

Cálculo da Probabilidade

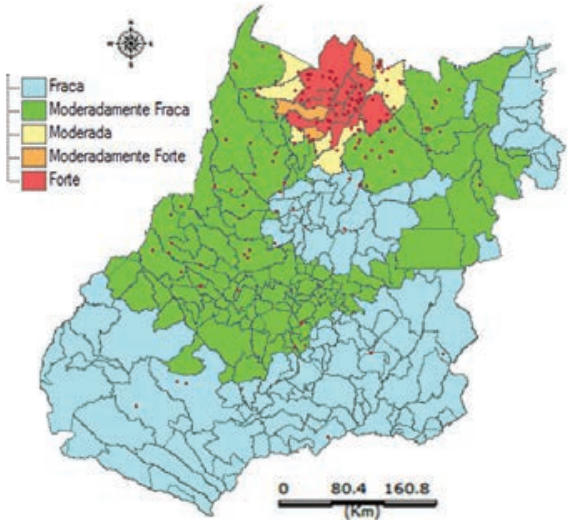

Figura 6 - Mapas derivados da aplicação do estimador de Kernel (função Quártica), dos pontos de epicentros registrados na Estação Sismológica da UnB, entre o período de 1973 a 2013

E ambos os mapas o comportamento dos padrões pontuais representa um agrupamento ou interação espacial, das classes de valores do estimador de Kernel, agrupadas em municípios. Agrupamento este visualizado no 
mapa de Média de Movimento Espacial, representados pelos municípios de Estrela do Norte, Formoso, Santa Tereza de Goiás, Mutunópolis, Trombas, Campinaçu, Campinorte e Mara Rosa. Na representação da média móvel espacial, a classe de densidade forte, representada por estes municípios indica um alto número esperado de sismos nestas unidades de área.

Já o mapa de Probabilidade de Kernel, indica a possibilidade de ocorrência de um sismo em determinada área. Neste mapa verificamos esta alta probabilidade, indicada no cluster da classe de densidade forte, formada pelos mesmos municípios apontados no mapa de Média de Movimento Espacial, acrescido pelo município de Porangatu.

Por fim, o mapa de Densidade de Kernel indica a densidade de sismo por unidade de área, indicando um ponto focal da classe de densidade forte, representada sobre o município de Estrela do Norte, procedida pela classe moderadamente forte constituída pelos municípios de Santa Tereza de Goiás, Mutunópolis e Formoso.

\section{ConcluSÃo}

A partir das técnicas tanto de geoprocessamento quanto de análise geoespacial, pode-se entender a dinâmica dos padrões focais sísmicos relacionados a uma zona, com densidade maior do que, em outras regiões goianas onde este evento não se faz tão presente. Estas técnicas permitiram averiguar a probabilidade de ocorrência deste fenômeno, em um determinado local, e sua distribuição no espaço.

As técnicas de geoprocessamento adotadas na análise espacial possibilitaram também a ordenação quantitativa dos dados espaciais, promovendo o potencial analítico do fenômeno sísmico, registrado na área de estudo em questão. Os dados coletados e processados das ocorrências sísmicas mostraram-se bastante consistentes, para um melhor entendimento da dinâmica sismológica do estado de Goiás, evidenciando como este evento se distribui em termos de densidade e em peso de magnitude, neste espaço territorial.

As análises dos produtos cartográficos provenientes da aplicação do método de Kernel, mostraram que há uma disposição sismológica maior 
para porção setentrional goiana, apresentando uma zona sísmica de eventos pontuais nesta região, coincidente com a já reconhecida Zona Sísmica de Porangatu, formada pelos municípios pertencentes à microrregião de Porangatu.

Os produtos cartográficos gerados nos remete a conclusão, que a técnica de análise espacial aplicada foi eficiente, para a análise proposta. Desta forma pode-se jugar, que de posse de dados confiáveis, processamento adequado e interpretação coerente, os problemas geográficos podem sim serem analisados para um planejamento detalhado, no que diz respeito às condições físicas estruturais.

Os dados tomográficos associados à crosta fina (Figura1), onde é verificado um potencial para a concentração de tremores é observado também, pelas análises cartográficas geradas. Evidenciando uma densidade maior na região boreal de Goiás onde a litosfera é menos densa.

De fato, ainda não temos condições de prever abalos sísmicos e mesmo se tivéssemos não seria evitado, porém, os estudos científicos brasileiros estão avançando no que diz respeito à sismologia intraplaca. E com auxilio das ferramentas da geotecnologia essas pesquisas podem trazer um resultado mais positivo, na investigação deste assunto.

\section{BIBLIOGRAFIA}

ASSUMPÇÃO, Marcelo Sousa de \& SACEK, Victor (2013) - "Intra-plate seismicity and flexural stresses in central Brazil". Geophysical Research Letters, Vol. $40, \mathrm{~N}^{\mathrm{o}} 3,487-91$.

BAILEY, Trevor \& GATRELL, Anthony (1995) - "Interactive spatial data analysis". Edinburgh Gate, Essex: Longman Scientific and Technical, England, 413p.

BOTEV, et al. (2010) - "Kernel density estimation via diffusion". - The Annals of Statistics, Vol. 38, $\mathrm{N}^{\circ}$ 5, 2916-2957. Disponível online no endereço url: http://arxiv.org/pdf/1011.2602.pdf (acedido em 5 Maio, 2014).

CÂMARA, Gilberto \& CARVAlho, Marilia Sá. (2002). - "Análise espacial de eventos”. São José dos Campos, INPE, cap. 2, 15p. Disponível online no endereço url: http://www.dpi.inpe.br/gilberto/livro/analise/cap2-eventos. pdf (acedido em 16 Maio, 2014). 
CÂMARA, Gilberto et al. (2001). "Introdução à ciência da Geoinformação". São José dos Campos, INPE. Disponível online no endereço url: http://www. dpi.inpe.br/gilberto/livro (acedido em 14 de Setembro, 2013).

FERNANDES \& FREITAS, Filho (2011). Websisbra. Sistema de Informação Geográfica Web para a Análise de Fenômenos Sismológicos, UnB.

JOHNSTON \& KANTER (1989) - "The seismicity of stable continental interiors", in GREGERSEN, S. \& BASHAM, P. W. (eds.): Earthquakes at North-Atlantic Passive Margins, Neotectonics and Post-glacial Rebound, Ed. Kluwer Academic, Boston, EUA, 299-327.

LACERDA FILHO, Joffre Valmório de et al. [org]. (2000) - "Programa levantamentos geológicos básicos do Brasil". Geologia e Recursos Minerais do Estado de Goiás e do Distrito Federal, escala 1:500.000. $2^{\text {a }}$ ed. Goiânia: CPRM/ METAGO/UnB.

LOPES, Afonso Emidio Vasconcelos de (2008) - "Mecanismos focais e esforços litosféricos no Brasil”. Tese de doutorado. São Paulo, USP, Instituto de Astronomia, Geofísica e Ciências Atmosféricas.

MATSUMOTO, Patrícia Sayuri Silvestre \& FLORES, Edilson Ferreira (2012) "Estatística espacial na geografia: um estudo dos acidentes de trânsito em Presidente Prudente - SP". GeoAtos - Revista geografia em Atos, Vol. 1, $\mathrm{N}^{\circ}$ 12, 95-113. Disponível online no endereço url:http://revista.fct.unesp. br/index.php/geografiaematos/article/viewFile/1755/matsumoto (acedido em 10 de Maio, 2014).

MILANI \& THOMAZ, Filho (2000) - "Sedimentary basins of South America", in CORDANI, U.G et al. (eds.): Tectonic Evolution of South America, Rio de Janeiro, 31st. IGC, 389-449.

PROGRAMA TerraView (2010) - Tutorial. São José dos Campos, SP: INPE, versão 4.2.2. Disponível online no endereço url: http://www.dpi.inpe.br/terraview/ index.php (acedido em Setembro, 2013).

SANTOS, Bethsaide Souza et al. (2012) - "Análise espacial aplicada à expansão de condomínios fechados na cidade de Feira de Santana (BA)". Anais do IV Simpósio Brasileiro de Ciências Geodésicas e Tecnologias da Geoinformação, Recife - PE, 1-9p. Disponível online no endereço url: http://www.ufpe.br/ cgtg/SIMGEOIV/CD/artigos/SIG/149_5.pdf (acedido em Abril, 2014).

SOARES, José et al. (2006) - "Seismic characteristics of central Brazil crust and upper mantle: A deep seismic refraction study". Journal of Geophysical Research: Solis Earth, Vol. 111, B12302, 13-31. Disponível online no endereço url: http://onlinelibrary.wiley.com/doi/10.1029/2005JB003769/pdf (acedido em Novembro, 2013). 
Série Documentos

Imprensa da Universidade de Coimbra

Coimbra University Press

2015

- U M

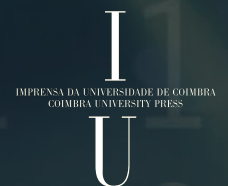

